EESTI NSV TEADUSTE AKADEEMIA TOIMETISED. XI KOIDE

FOOSIKALIS-MATEMAATILISTE JA TEHNILISTE TEADUSTE SEERIA. 1962, NR. 2

ИЗВЕСТИЯ АКАДЕМИИ НАУК ЭСТОНСКОН ССР. ТОМ ХІ СЕРИЯ ФИЗИКО-МАТЕМАТИЧЕСКИХ И ТЕХНИЧЕСКИХ НАУК. 1962, № 2

\title{
О КРИСТАЛЛИЗАЦИИ СЛАНЦЕЗОЛЬНЫХ РАСПЛАВОВ ПОРТЛАНД-ЦЕМЕНТНОГО СОСТАВА
}

\author{
М. КИИЛЕР, \\ кандидат технических наук
}

Н. Л. ДИЛАКТОРСКИИ,

доктор геолого-минералогических наук

При плавлении минеральной части прибалтийских горючих сланцев валовой добычи (от слоя А до $\mathrm{H}$ вместе с прослоями известняка) получается расплав, химическйй состав которого очень близок к портланд-цементному клинкеру. Принципиальная возможность получения плавленого портланд-цемента при охлаждении таких расплавов показана авторами настоящей статьи еще в 1958 году [ $\left.{ }^{2}\right]$. Однако для эффективного управления процессом плавления и охлаждения сланцезольных распілавов при получении из них портланд-цементного клинкера наилучшего качества необходимы гочные данные о последовательности и температурах начала кристаллизации отдельных минералов, входящих в состав этих расплавов.

Невозможность использования для сланцезольных расплавов, являющихся многокомпонентңыми системами, диаграмм равновесия трех- н четырехкомпонентных систем заставила нас прибегнуть к экспериментальному изучению процесса кристаллизашии.*

Процесс кристаллизации изучался на шести сланцезольных клинкерах, полученных путем плавления минеральной части горючего сланца месторождения «Вийвиконна», содержащей различные количества карбоната кальция, в пламени ацетиленокислородной горелки. Химический состав (табл. 1) исследованных расплавов (клинкеров) отличался в основном по содержанию окиси кальция (от 58 до 65\%). Расчетный коэффициент насыщения соответствующих клинкеров оказался в пределах от 0,70 до 1,05 .

\section{Методика исследования}

Работа проводилась методом отжига и закалки в микропечи конструкции Галахова [']. Нагревательная спираль, изготовленная из вольфрамовой проволоки диаметром 0,8 мм, питалась током до $20 \mathrm{~V}$ и $50 \mathrm{~A}$ и позволяла получать в печи температуры до $2200^{\circ}$ C. В начале работы полость печи заполнялась агроном, очищенным от кислорода, паров воды и углекислого газа. Температура в печи определялась по величине напряжения на электродах (шкала напряжений градуировалась по температурам плавления чнстых металлов: $\mathrm{Cu}, \mathrm{Pd}, \mathrm{Pt}$ и $\mathrm{Rh})$. Ошибка определения температуры не превьшала $\pm 10-12^{\circ}$.

Кусочек плавленого клинкера диаметром 3-4 мм помещался в микропечь на стержне из вольфрамовой проволоки. Печь нагревалась до полного плавления образ-

* В работе принимали участие сотрудники ИССМ АН ЭССР С. Мармор, Р. Ильберг и И. Рожнова. 
Tаблича 1

Химический состав исследованных расплавов (клинкеров)

(вес. \%)

\begin{tabular}{|c|c|c|c|c|c|c|}
\hline Ve расплава & 307 & 301 & 306 & 304 & 303 & 305 \\
\hline $\begin{array}{l}\mathrm{SiO}_{2} \\
\mathrm{Al}_{2} \mathrm{O}_{3} \\
\mathrm{Fe}_{2} \mathrm{O}_{3} \\
\mathrm{CaO} \\
\mathrm{MgO} \\
\mathrm{FeO} \\
\mathrm{FeS} \\
\mathrm{R}_{2} \mathrm{O} \\
\mathrm{SO}_{3}\end{array}$ & $\begin{array}{r}23,91 \\
6,75 \\
0,73 \\
58,35 \\
6,17 \\
2,42 \\
1,10 \\
0,85 \\
0,06\end{array}$ & $\begin{array}{r}23,18 \\
6,60 \\
1,41 \\
59,03 \\
6,92 \\
1,41 \\
0,66 \\
0,96 \\
0,05\end{array}$ & $\begin{array}{r}22,12 \\
6,34 \\
2,28 \\
60,25 \\
7,20 \\
1,09 \\
0,69 \\
1,03 \\
0,05\end{array}$ & $\begin{array}{r}22,19 \\
5,70 \\
1,30 \\
62,54 \\
6,49 \\
1,83 \\
1,10 \\
1,12 \\
0,05\end{array}$ & $\begin{array}{r}20,05 \\
5,94 \\
1,02 \\
63,66 \\
6,02 \\
1,41 \\
1,10 \\
1,16 \\
0,12\end{array}$ & $\begin{array}{r}19,13 \\
4,76 \\
1,46 \\
64,72 \\
5,82 \\
1,46 \\
0,80 \\
0,84 \\
0,02\end{array}$ \\
\hline Итого & 100,34 & 100,22 & 101,25 & 101,32 & 101,48 & 99,01 \\
\hline $\begin{array}{l}\text { Коэффи- } \\
\text { циент на- } \\
\text { сыщения КН }\end{array}$ & 0,70 & 0,73 & 0,79 & 0,89 & 0,95 & 1,05 \\
\hline $\begin{array}{l}\mathrm{SiO}_{2} \\
\mathrm{Al}_{2} \mathrm{O}_{3} \\
\mathrm{CaO}\end{array}$ & $\begin{array}{r}26,9 \\
7,6 \\
65,5\end{array}$ & $\begin{array}{r}26,1 \\
7,4 \\
66,5\end{array}$ & $\begin{array}{r}25,0 \\
7,1 \\
67,9\end{array}$ & $\begin{array}{r}23,7 \\
6,4 \\
69,9\end{array}$ & $\begin{array}{r}22,4 \\
6,6 \\
71,0\end{array}$ & $\begin{array}{r}21.6 \\
5.4 \\
73.0\end{array}$ \\
\hline Итоro & 100,0 & 100,0 & 100,0 & 100,0 & 100,0 & 100,0 \\
\hline
\end{tabular}

па, а затем охлаждалась до желаемой температуры отжига (в интервале от 1300 до $2200^{\circ}$ ). Время отжига образцов варьировали от 30 секунд (при высоких температурах, близких к началу кристаллизации расплавов) до 90 минут (при низких температурах отжига). Для закалки отожженных образцов они быстро выбрасывались ия нагревательной спирали при помощи специального устройства.

Охлажденные образцы изучались под микроскопом в отраженном свете. Выявле ние структуры клинкера проводилось водой, смесью вода - спирт $(1: 1)$ и насыщенным раствором сульфата магния. Петрографическими исследованиями был установлен фазовнй состав отожженных при различных температурах образцов, а также выяснено, какне минералы образзовались в них во время отжига (крупные кристаляы) и какие - при последующей закалке (мелкие кристаллы). Химические определення субмикроскопической свободной окиси кальция проводились этилово-глицератным методом, а свободной окиси магния - методом W. C. Taylor и R. H. Bogue.

\section{Результаты исследования}

Исследования показали, что в расплаве № 307, содержащем наименьшее количество окиси кальция $(58,35 \%, \mathrm{KH}=0,70)$, кристаллизация начинается только при $1775^{\circ}$ (табл. 2) выделением крупных, размером до $80 \mu$, округлых зерен двухкальциевого силиката, В образцах, закаленных после отжига при $1800^{\circ}$ и выше, были найдены только мелкие чешуйчатые кристаллы белита и небольшое количество скелетных образований алита (фото 1 a). При отжиге расплава при $1750^{\circ}$ и ниже. наряду с $\mathrm{C}_{2} \mathrm{~S}$, были обнаружены небольшие зерна периклаза (фото 16 ). При понижении температуры отжига вплоть до $1300^{\circ}$ новых кристаллических фаз найдено не было.

В расплаве № 301, содержащем $59,03 \% \mathrm{CaO}(\mathrm{KH}=0,73)$, кристаллизация начинается при $1800^{\circ}$ одновременным выделением двух фаз $-2 \mathrm{CaO} \cdot \mathrm{SiO}_{2}$ и $3 \mathrm{CaO} \cdot \mathrm{SiO}_{2}$ 
На $25^{\circ}$ ниже к ним присоединяется периклаз (фото 1 в). Те же самые фазы сохранились и при более низких температурах. Так как ниже $1250^{\circ}$ трехкальциевый силикат теоретически считается неустойчивой фазой, процесс кристаллизации расплавов ниже $1300^{\circ}$ не исследовался.

Кристаллизация расплава № $306(60,25 \% \mathrm{CaO}, \mathrm{KH}=0,79)$ началась выделением трехкальциевого силиката при $1825^{\circ}$. За ним следовал периклаз (при $1800^{\circ}$ ) и тольhо затем двухкальциевый силикат (при $1775^{\circ}$ ) (фото 1г). Как и в предыдущих расплавах, при понижении температуры отжига до $1300^{\circ}$ качественных изменений в фазовом составе обнаружено не было.

Образцы клинкерного расплава № 304 (62,54\% СaO, КН=0,89), охлажденные от температуры выше $1950^{\circ}$, состояли из скелетных кристаллов $\mathrm{C}_{3} \mathrm{~S}$, мелких зерен $\mathrm{C}_{2} \mathrm{~S}$ и промежуточного вещества, образовавшихся при быстром охлаждении (фото $1 \partial$ ) Кристаллизация расплава начиналась, в отличие от всех предыдущих случаев, выделением не силикатов кальция, а кристаллической окиси кальция при $1950^{\circ}$. Затем, при $1850^{\circ}$, начал выделяться трехкальциевый силикат. Однако образование $\mathrm{C}_{3} \mathrm{~S}$ conровождалось одновременным полным растворением в жидкой фазе небольших количеств ранее выделившейся окиси кальция. Ввиду этого в интервале от 1850 до 1775 вновь происходила кристаллизация только одной фазы-трехкальциевого силиката Oт 1775 до $1700^{\circ}$ кристаллизовались одновременно $\mathrm{C}_{3} \mathrm{~S}$ и периклаз, а при $1700^{\circ}$ и ннже $-\mathrm{C}_{3} \mathrm{~S}$, периклаз и двухкальциевый силикат.

Кристаллизация расплава № $303(63,66 \% \mathrm{CaO}, \mathrm{KH}=0,95)$ начиналась при $2025^{\circ}$ выделеннем свободной окиси кальция. Первые крупные кристаллы алита появились в этом расплаве только при $1850^{\circ}$ (фото 1 e). К этому же времени количество кристаллической окиси кальция в расплаве достигло максимума и началось постепенное растворение ее до полного исчезновения при $1675^{\circ}$. Вскоре после этого, при $1650^{\circ}$. началось выделение отдельных зерен двухкальциевого силиката. При $1300^{\circ}$ твердая фаза расплава № 303 состояла из трехкальциевого силиката, периклаза, кристаллизация которого началась при $1800^{\circ}$, и небольшого количества двухкальциевого силиката.

Температура начала кристаллизации расплава № 305, содержавшего наибольшее колнчество окиси кальция $(64,74 \% \mathrm{CaO}, \mathrm{KH}=1,05)$, оказалась очень высокой $2075^{\circ}$. Первой выделялась окись кальция, которая при понижении температуры отжига до $1850^{\circ}$ была единственной кристаллизующейся фазой. При $1850^{\circ}$ началось выделение $3 \mathrm{CaO} \cdot \mathrm{SiO}_{2}$ и в то же время постепенное растворение окиси кальция, которое завершилось при $1300-1400^{\circ}$. При $1800^{\circ}$ к двум предыдущим фазам $-\mathrm{C}_{3} \mathrm{~S}$ и $\mathrm{CaO}$ прибавилась третья - $\mathrm{MgO}$. Равновесной кристаллизации двухкальциевого силиката из расплава № 305 не было обнаружено. Поэтому единственными твердыми фазами в продукте отжига этого расплава при $1300^{\circ}$ были трехкальциевый силикат и периклаз.

Кристаллизация алюминатов и алюмоферритов кальция при охлаждении сланщезольных расплавов нами не исследовалась.

На основе полученных данных о начале крнсталлизации отдельных фаз в расплавах с различным содержанием $\mathrm{CaO}$ составлена ди аграмма состоян и я сланцезольны х р аспл в вов портланд-цементного состава (фиг. 1). Она представляет собой псевдодвойную диаграмму фазовых равновесий, в которой первым компонентом является окись кальция, вторым - сумма всех других окислов в расплаве.

Из диаграммы следует, что кристаллизация значительной части клинкерных расплавов начинается с выделения $3 \mathrm{CaO} \cdot \mathrm{SiO}_{2}$. Свободная окись кальция появляетсл в качестве первично кристаллизующейся фазы только при увеличении содержання $\mathrm{CaO}_{\text {общ }}$ в расплаве выше $61,7 \%(\mathrm{KH}>0,85)$. Сильно сдвинута, но в противоположную сторону, и область первичной кристаллизации двухкальциевого силиката - последний появляется в качестве первой фазы только в расплавах, содержащих менес $59 \% \mathrm{CaO}$ (КН соответствующих клинкеров около 0,7 и ниже). 


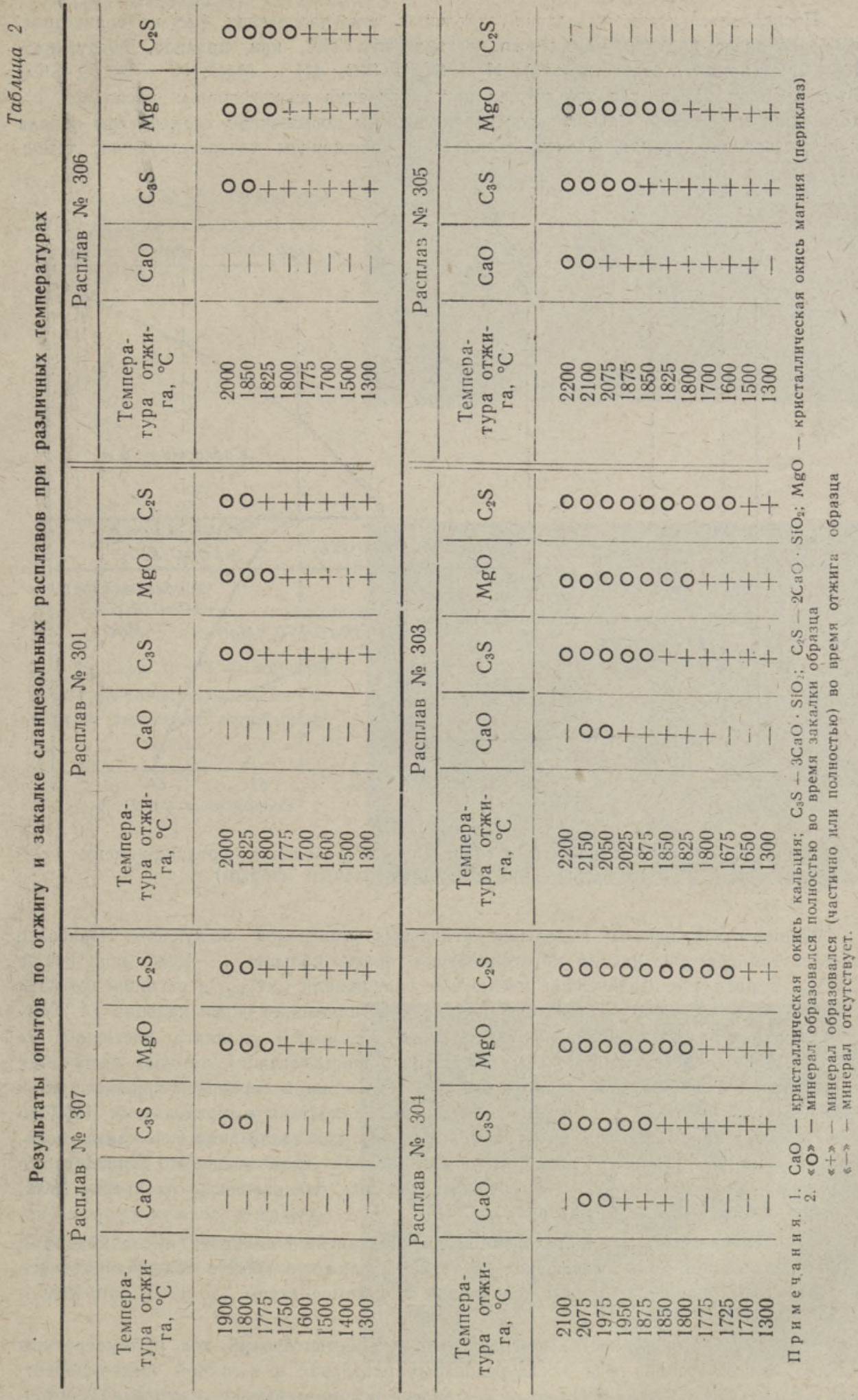


Последовательность выделения отдельных кристаллических фаз из сланцезольных расплавов портланд-цементного состава до $1300^{\circ}$, как правило, следующая: $\mathrm{I}-\mathrm{CaO}$ (может и отсутствовать); $\mathrm{II}-3 \mathrm{CaO} \cdot \mathrm{SiO}_{2} ; \mathrm{III}-\mathrm{MgO} ; \mathrm{IV}-2 \mathrm{CaO} \cdot \mathrm{SiO}_{2}$ Этот порядок изменяется только при кристаллизации низкоосновных расплавов, содержащих менее $60 \% \mathrm{CaO}$, в связи с постепенным повышением температуры начала кристаллизации двухкальциевого силиката и понижением соответствующей температуры для $\mathrm{C}_{3} \mathrm{~S}$.

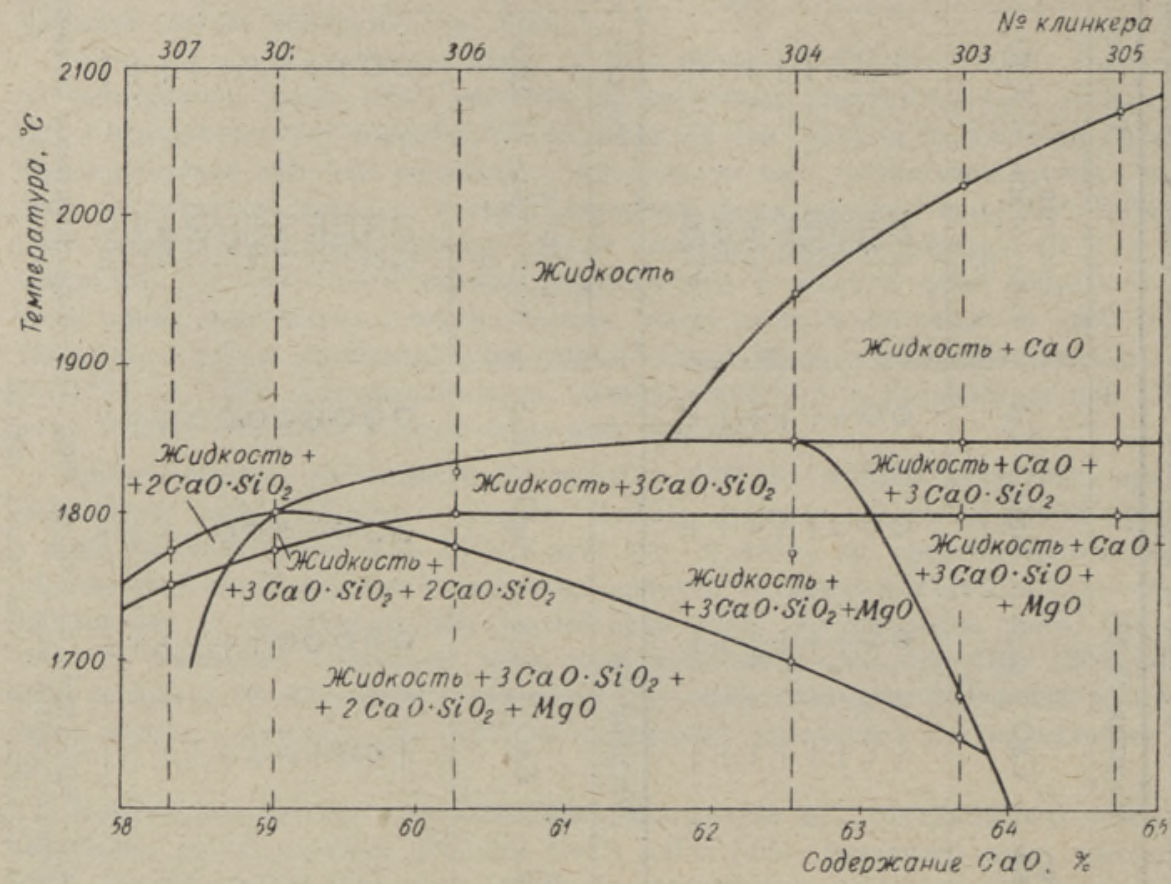

Фиг. 1. Фазовые равновесия в сланцезольных расплавах портланд-цементного состава (по экспериментальным данным)

Температуры начала выделения отдельных минералов следующие. Наиболее низкая температура начала кристаллизации окиси кальция - $1850^{\circ}$ при $61,7 \%$ $\mathrm{CaO}_{\text {общ }}$ в расплаве. Дальнейшее увеличение содержания $\mathrm{CaO}_{\text {общ }}$ в расплаве до $65 \%$ приводит к повышению температуры начала кристаллизации окиси кальция до $2080^{\circ}$

Температура начала кристаллизации трехкальциевого силиката постоянна на уровне $1850^{\circ}$ во всех сланцезольных расплавах, кристаллизация которых начинается с выделения окиси кальция $\left(\mathrm{CaO}_{\text {общ }}>61,5 \%\right)$. В области первичной кристаллизации $3 \mathrm{CaO} \cdot \mathrm{SiO}_{2}$. температура начала его выделения находится в пределах от 1800 до $1850^{\circ}$. Почти такой же ход имеет кривая начала кристаллизации периклаза, нахо. дящаяся на 25-50 расплавах, содержащих $60 \%$ и более окиси кальция, она находится на уровне $1800^{\circ}$, в менее основных расплавах - немного ниже.

Температура начала кристаллизации двухкальциевого силиката имеет максимум $\left(1800^{\circ}\right)$ при $59 \%$ СаО. Уменьшение, а также увеличение общего содержания окиси кальция в расплаве приводит к понижению этой температуры (до $1750^{\circ}$ при $58 \%$ и $1650^{\circ}$ при $\left.64 \% \mathrm{CaO}\right)$.

Чтобы установить, насколько различаются действительный ход и температуры начала кристаллизации фаз в сланцезольных расплавах и в чистой трехкомпонентной системе $\mathrm{CaO}-\mathrm{Al}_{2} \mathrm{O}_{3}-\mathrm{SiO}_{2}$, была составлена вспомогательная диаграмма (фиг. 2). 
$\boldsymbol{a}$ - клинкер № 307. Отжиг при $1800^{\circ}$. Мелкие чешуйчатые кристаллы - белит, темные скелеты - алит.

6 - клинкер № 307. Отжиг при $1725^{\circ}$. Крупные кристаллы белита и маленькие зерна периклаза.

$\boldsymbol{B}$ - клинкер № 301. Отжиг при $1775^{\circ}$. Большие удлиненные кристаллы - алит. Белит в двух формах: крупные округлые кристаллы, образовавшиеся во время отжига, и маленькие зерна, образовавшиеся во время закалкн образца:
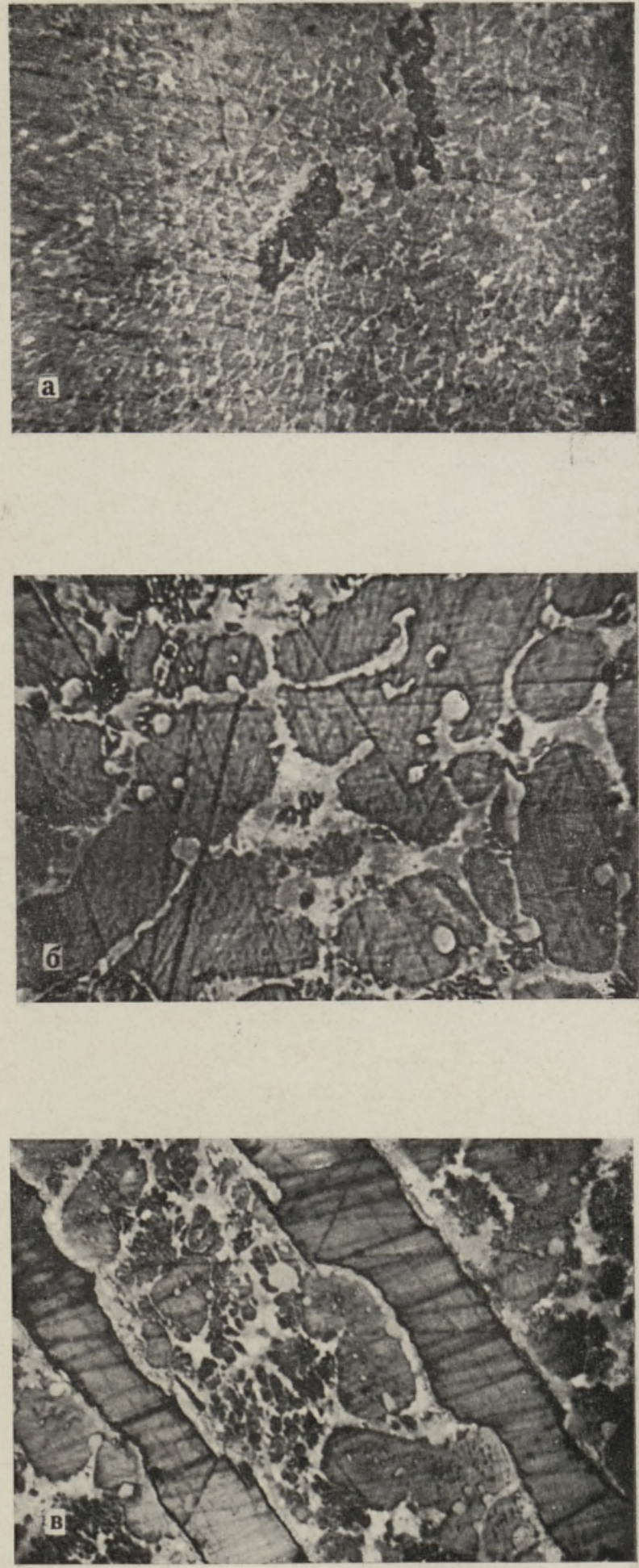

Фото 1. Структура плавленых клинкеров, полученных быстрым охлаждением образцов, отожженных при различных температурах (свет отраженный; увел. 600 Х). 

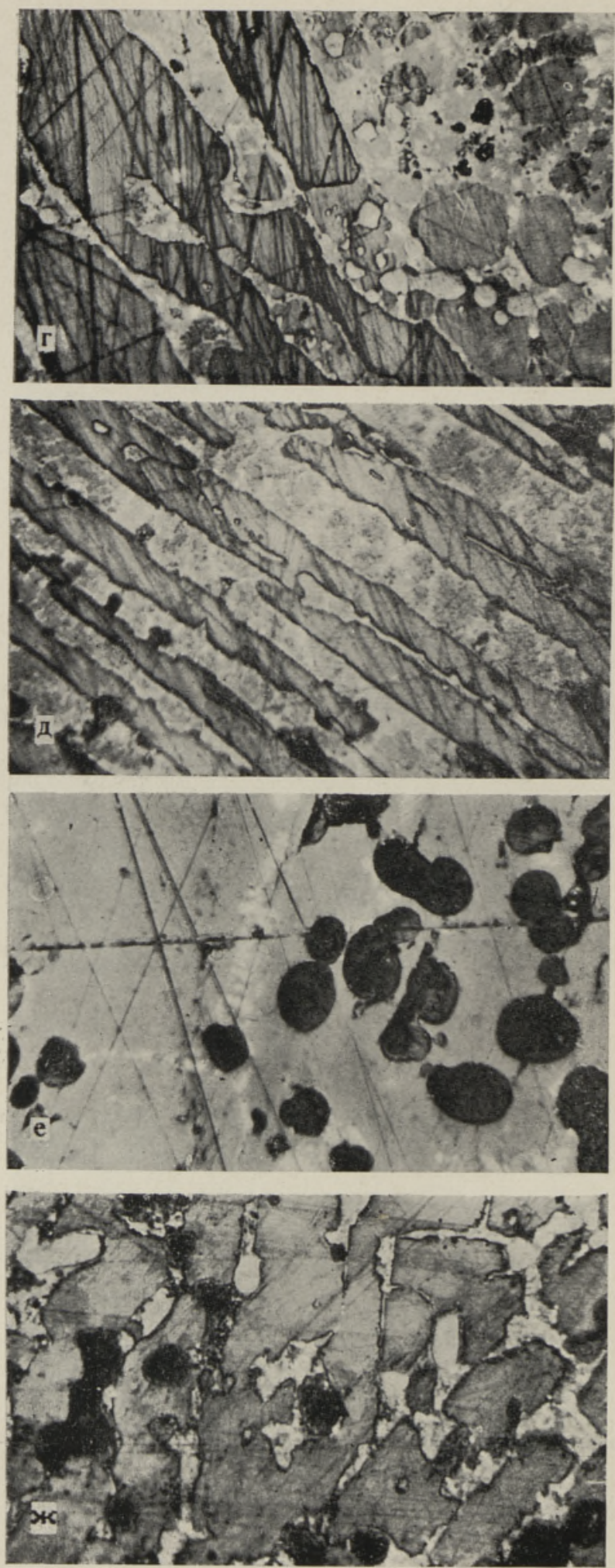

2 - клинкер № 306. Отжиг при $1750^{\circ}$. Кроме крупных кристаллов алита и белита очень хорошо видны угловатые зерна периклаза (светлые).

Ә - клинкер № 304, быстро охлажденный после полного плавления. Удлиненные крнсталлы - алит.

$e-$ клинкер № 303. Отжиг при $1850^{\circ}$. Tемные округлые зерна - кристаллическая окись кальция. Светлые таблитчатые кристаллы - алит.

ж - клинкер № 303. Отжиг при $1700^{\circ}$. Таблитчатые кристаллы алита, зерна пернклаза (светлые) и окиси кальция (темные). 
Она представляет собой разрез этой тройной диаграммы по линии, проходящей через фигуративные точки составов сланцезольных расплавов. Для нанесения последних на диа̨рамму $\mathrm{CaO}-\mathrm{Al}_{2} \mathrm{O}_{3}-\mathrm{SiO}_{2}$ данные анализа были пересчитаны на три компонента, прннимая сумму $\mathrm{CaO}+\mathrm{Al}_{2} \mathrm{O}_{3}+\mathrm{SiO}_{2}$ за сто процентов (табл. 1).

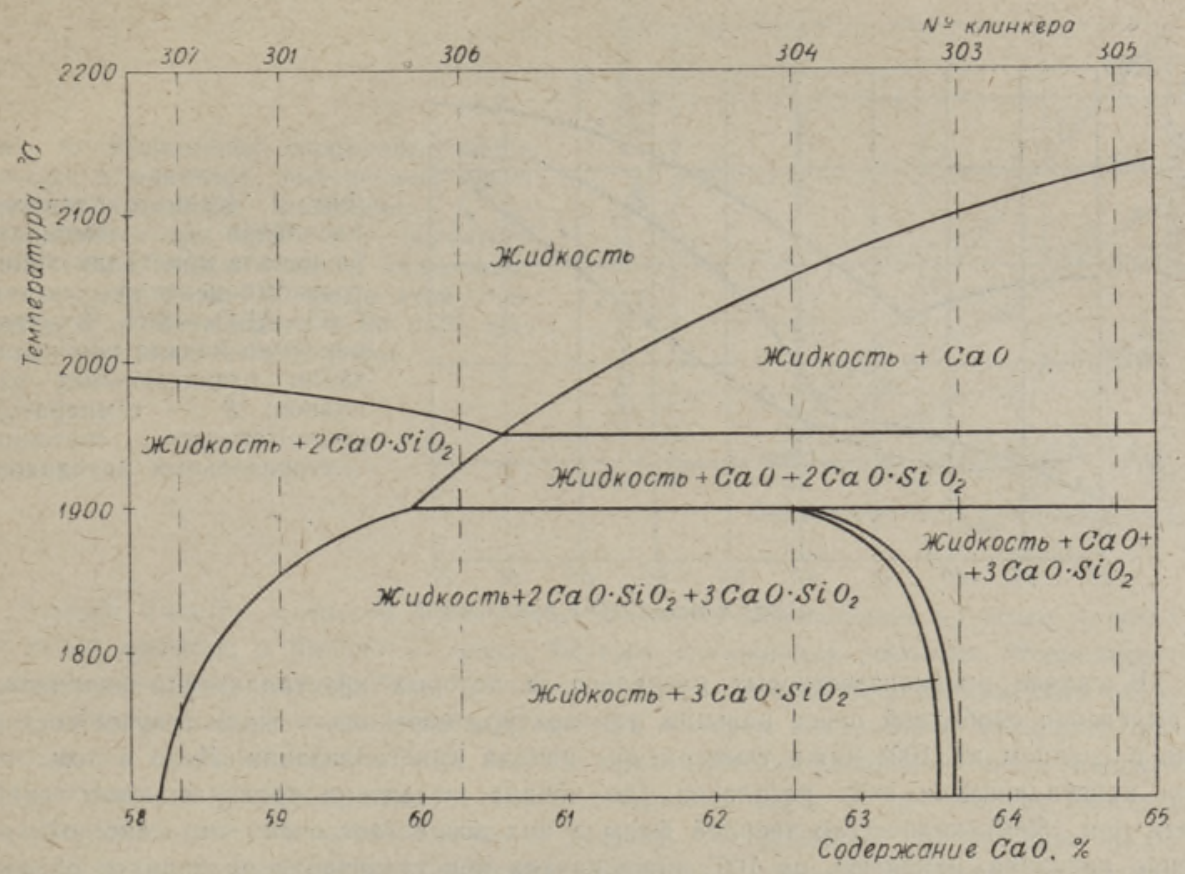

Фиг. 2. Фазовые равновесия в сланцезольных расплавах (по тройной диаграмме $\mathrm{CaO}-\mathrm{Al}_{2} \mathrm{O}_{3}-\mathrm{SiO}_{2}$ ).

По составленной дииаграмме трехкальциевый силикат нигде не выделяется в виде первичной фазы, а всегда следует за двухкальциевым силикатом или же за $2 \mathrm{CaO} \cdot \mathrm{SiO}_{2}$ и окисью кальция. Все температуры начала кристаллизации отдельных минералов в чнстой трехкомпонентной системе значительно выше, чем в сланцезольных расплавах. Разница в температурах начала кристаллизации расплавов тем больше, чем дальше от вершины $\mathrm{CaO}$ в треугольнике $\mathrm{CaO}-\mathrm{Al}_{2} \mathrm{O}_{3}-\mathrm{SiO}_{2}$ находится состав расплава, Т. е. чем меньше в нем окиси кальция. Поэтому в то время как в высокоизвестковых расплавах $(64-65 \% \mathrm{CaO})$ разница между температурами начала кристаллизации расплава по этим диаграммам равна примерно $50-70^{\circ}$, при $60-62 \%$ $\mathrm{CaO}$ она увелнчивается в среднем до $150^{\circ}$ (фиг. 3, кривые 1 и 2). При дальнейшем уменьшении содержания окиси кальция в расплаве эта разница увеличивается еще больше: при $58 \%$ СаO кристаллизация сланцезольных расплавов начинается только около $1800^{\circ}$ вместо $2000^{\circ}$ для чистой трехкомпонентной системы.

Кроме температуры начала кристаллизации для характеристики сланцезольных расплавов были определены температуры перехода их в жидкотеку чее состояние. Последние определялись в момент отрыва капли при плавлении клинкеров в ацетилено-кислородном пламени. Полученные данные приведены на фиг. 3 в виде кривой 3 , представляющей собой фактически кривую одинаковой вязкости расплавов, так как все клинкеры были расплавлены примерно прк. одинаковой скорости образования капель.

Сравнение кривых 2 и 3 фиг. 3 показывает, что в области первичной кристаллизащни двух- и трехкальциевого силикатов температура жидкотекучего состояния 
сланцезольных расплавов очень близка к температуре начала кристаллизации их По данным исследования процесса кристаллизации расплавов это связано с тем, чтс при температурах даже только на $50^{\circ}$ ниже температуры начала кристаллизации (полного плавления) количество твердой фазы в расплавах достигает $40-60 \%$.

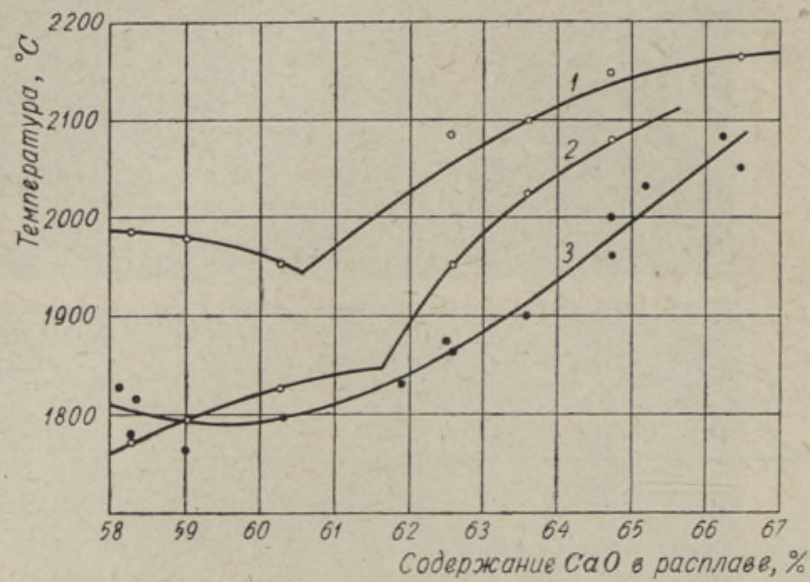

Фиг. 3. Кривые плавкости расплавов: 1 - температура начала кристаллизацин в трехкомпонентной системе $\mathrm{CaO}-\mathrm{Al}_{2} \mathrm{O}_{3}-\mathrm{SiO}_{2} ; 2-$ температура начала кристаллизации сланцезольных расплавов; 3 - температура жидкотекучего состояния сланцезольных расплавов.

В случае высокоизвестковых расплавов, в которых кристаллизация начинается с выделения свободной окиси кальция, температура перехода в жидкотекучее состоянне в среднем на $100^{\circ}$ ниже температуры начала кристаллизации. Дело в том, что при кристаллизации этих расплавов (до начала выделения трехкальциевого силиката при $1850^{\circ}$ ) количество твердой фазы в них возрастает очень медленно: охлаждение расплава, например, на $100^{\circ}$ ниже начала кристаллизации приводит к образованию в них не более $10 \%$ крнсталлической окиси кальция. Поэтому при плавлении соответствующих клинкеров жидкотекучее состояние расплава будет достигнуто значительно раньше полного плавлення всей твердой фазы. Однако для получения из sтих расплавов доброкачественного клинкера недопустимо образование крупнокристаллимеской окиси кальция, которая даже в небольших количествах может привести к неравномерному изменению объема цемента. Поэтому температуры расплавов должны быть всегда выше температур начала их кристаллизации.

Изучение процесса кристаллизации сланцезольных расплавов позволяет разработать и рекомендации по оптимальному режиму охлаждения расплавов для получения из них высококачественного клинкера. В основу оценки качества клинкера положены следующие факторы: 1) количество и размер кристаллов свободной окиси кальция в клинкере; 2) то же самое для свободной окиси магния; 3) количество алита в клинкере.

По проведенным исследованиям количество и размер кристаллов с в бодн о й о киси кальция в плавленых клинкерах зависит, во-первых, от общего содержания $\mathrm{CaQ}$ в пих, и, во-вторых, от режима охлаждения расплава. В плавленых клинкерах, содержащих менее $61,5 \% \mathrm{CaO}(\mathrm{KH}<0,85)$, при любом режиме охлаждения свободная окнсь кальция не образуется. В клинкерах, содержащих от 61,5 до $64,0 \%$ $\mathrm{CaO}$ (КН от 0,85 до 1,0) при медленном охлаждении выделяется крупнокристаллическая окись кальция, которая после начала кристаллизации $3 \mathrm{CaO} \cdot \mathrm{SiO}_{2}$ при $1850^{\circ}$ постепенно растворяется. Поэтому в клинкерах, полученных очень медленным охлаждением до $1300^{\circ}$ расплавов, содержащих менее $64 \%$ СаO, свободной окиси кальция нет. Максимальное количество крупнокристаллической окиси кальция содержат клинкера, охлажденные медленно только до $1850^{\circ}$. Абсолютное содержание СаО своб при этом зависит от общего количества окиси кальция в расплаве и увеличивается от нуля при $61,5 \% \mathrm{CaO}_{\text {общ }}$ до $10 \%$ при $64,5 \% \mathrm{CaO}_{\text {общ }}$ (фиг. 4, кривая 1). Таким образом, для получения клинкера, не содержащего крупнокристаллической, медленно 
гидратирующейся окиси кальция, расплавы, содержащие от 61,5 до $64 \% \mathrm{CaO}$, сле дует охлаждать очень медленно (в условиях равновесной кристаллизации).

Фиг. 4. Количество свободной окиси кальция в клинкере, полученном быстрым охлаждением расплава: 1 отожженного при $1850^{\circ} ; 2$ - нагретого на $25^{\circ}$ выше точки полного плавления; 3 - нагретого на $75^{\circ}$ выше этой температуры; 4 - нагретого на $125^{\circ}$ выше этой температуры.

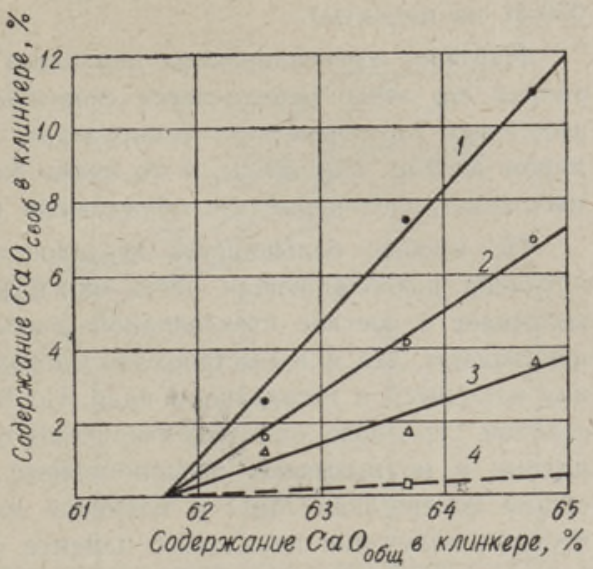

Однако имеется и другой путь предотвращения образования крупных кристаллов окиси кальция, а именно - очень быстрое охлаждение расплава. Возможность осуществления этого способа была доказана опытами по закалке расплавленных образцов в микропечи. Эти опыты показали, что при быстром охлаждении полностью расплавленного клинкера можно либо вообще предотвратить выделение окиси кальция, либо получить ее в субмикроскопическом виде (размер зерен $<1 \mu$ ). Можно ожидать, что субмикроскопические кристаллы окнси кальция, образующиеся при быстром охлаждении клинкерных расплавов, не вызовут объемных изменений цемента (по данным Когана и Гольдштейна $*, 5 \% \mathrm{CaO}_{\text {своб }}$ не вызывают объемных изменений даже при раз мере кристаллов окиси кальцкя до $10 \mu$ ).

Абсолютное количество мелкокристаллической свободной окиси кальция в быстроохлажденных клинкерах тем ниже, чем меньше общее содержание $\mathrm{CaO}$ в клинкере и чем больше температура расплава превышает температуру начала кристалли. зации его (фиг. 4 , кривые 2-4). Для получения плавленого клинкера, содержащего не более одного процента $\mathrm{CaO}_{\text {своб. }}$ из расплава, имеющего коэффициент насыщения около единицы или даже больше, требуется быстрое охлаждение его от температур на $150-200^{\circ}$ выше начала кристаллизации. Для получения клинкеров с меньшим коэффициентом насыщения или при большей, чем в микропечи, скорости охлаждения расплава, требуемый нагрев меньше.

Возможность получения при быстром охлаждении высокоосновных расплавов плавленых клинкеров, почти не содержащих $\mathrm{CaO}_{\text {своб }}$, объясняется, по-видимому, низкой кристаллизационной способностью окиси кальция. Ввиду этого количество $\mathrm{CaO}$, которое успевает при быстром охлаждении выделиться из расплава до начала кристаллизяิции $\mathrm{C}_{3} \mathrm{~S}$, очень невелико. Однако после начала кристаллизации $3 \mathrm{CaO} \cdot \mathrm{SiO}_{2}$ содержание окиси кальция в расплаве падает столь быстро, что кристаялическая окись кальция в нем уже образоваться не может.

Из сказанного следует, что для получения плавленого цемента, обладающего равномерным изменением объема, может быть применено как очень медленное, так и очень быстрое охлаждение расплава.

Оки сь магния присутствует в цементных клинкерах главным образом в свободном состоянии, т. е. в виде периклаза, гидратация которого сопровождается

* Научный отчет «ГИПРОЦЕМЕНТа», 1959. Разработка технологии получения плавленых цементов в энергетических топках с жидким шлакоудалением при сжиганин прибалтийских горючих сланцев. 
сильными объемными изменениями.-Опасными здесь являются крупные кристаллы периклаза, гидратация которых продолжается и после затвердения цементного камня. Особенное значение это имеет для сланцезольных расплавов, где содержание окиси магния может превышать $4,5 \%$, т. е. норму, предусмотренную стандартом (ГОСТ 970-41 на цементы).

Изучение кристаллизации периклаза в сланцезольных расплавах показало, пто размер его зереп определяется скоростью охлаждения расплава. При отжиге сланцезольных расплавов при температуре $1700-1800^{\circ}$ в них возникали крупные, размером до $15 \mu$, кристаллы, в то время как при быстром охлаждении расплава видимых кристаллов пернклаза обнаружено не было.

По мнению большинства исследователей, при быстром охлаждении спекшегося клинкера преобладающая часть окиси магния не выделяется в свободном виде, а застывает в составе стекловидной фазы. Проведенные нами химические анализы показывают, что и в быстроохлажденных плавленых клинкерах почти вся окись магния находится в несвязанном виде. Но благодаря чрезвычайно малым размерам кристаллов периклаза они гидратируются одновременно с другими клинкерными минералами и не вызывают неравномерного изменения объема цементного камня при общем солержании $\mathrm{MgO}$ в клинкере даже более $6 \%$ [3]. Поэтому можно сказать, что для получсния плавленого цемента с равномерным изменением объема (при автоклавном испытании) необходнмо охлаждать расплав быстро при температурах ииже начала кристаллизации периклаза.

Петрографические исследования показали, что количество трехкальщиевого силикат а в плавлешых клинкерах завнсит от скорости охлаждения расплава. Клинкера, полученные в микропечи при быстром охлаждении расплава, содержат в среднем на 5-10\% больше алита, чем клинкера, полученные медленным охлаждением расплава до $1300^{\circ}$ (фиг. 5, кривые 1 и 2). Это связано с неравновесной кристаллизацией расплава при его быстром охлаждении [3]. При этом трехкальциевый силикат, выделяющийся вначале в большом колнчестве, не успевает реагировать с расплавом до полного загустевания последнего.

Было установлено также, что даже небольшие колюбания в скорости охлаждення расплава могут привести к сильным изменениям в минералогическом составе плавленого клинкера. Так, расплавленные в ацетилено-кислородном пламени и охлажденные в воде капли содержали, как правило, больше алита, чем капли, охлажденнне на керамической подставке в воздухе* (фиг. 5 , кривые 3 и 4).

В то же время количество алита в клинкерах, охлажденных на воздухе, оказалось бо́льшим, чем в образцах, закаленных в микропечи, где охлаждение проб происходило медленней. Следовательно, небольшое замедление скорости охлаждения расплава ведет к значительному растворению выделившегося из него алита.

В полученных данных бросается в глаза, что содержание алита значительно превышает расчетное в быстроохлажденных клинкерах с общим содержанием окиси кальция от 59 до $61 \%$. Так, из расплава с $59 \% \mathrm{CaO}(\mathrm{KH}=0,73)$ при быстром охлаждении в воде можно получить клинкер, содержащий алита в два раза больше расчетного: 40\% вместо 20. По мере обогащения клинкеров известью действительное количество алита в них приближается к расчетному ** (фиг. 5, кривая 2). Максимальное содержание алита в клинкере (около 70\%) лимитируется содержанием кремнезема в нем. Таким образом, быстрое (водяное) охлаждение клинкерных расплавов с

* Об этой закономерности авторы статьи доложили на совещании Латвийского республиканского правления Всесоюзного химического общества им. Д. И. Менделеева в декао̆ре 1959 г. в Рнге.

** Тот факт, что высокоизвестковые клинкеры, расплавленные на газосварочной установке, содержат меньше алита, чем предусмотрено расчетом (фиг. 5 , кривые 3 и 4), объясняется тем, что их плавление производилось при температурах, при которых произошла кристаллизация свободной окиси кальция (фиг. 3 , крнвая 3), вследствие чего кристаллизация $\mathrm{C}_{3} \mathrm{~S}$ была заторможена. 
умеренной основностью (КН от 0,70 до 0,85 ) способствует получению из них вяжущего с повышенным содержанием алита.

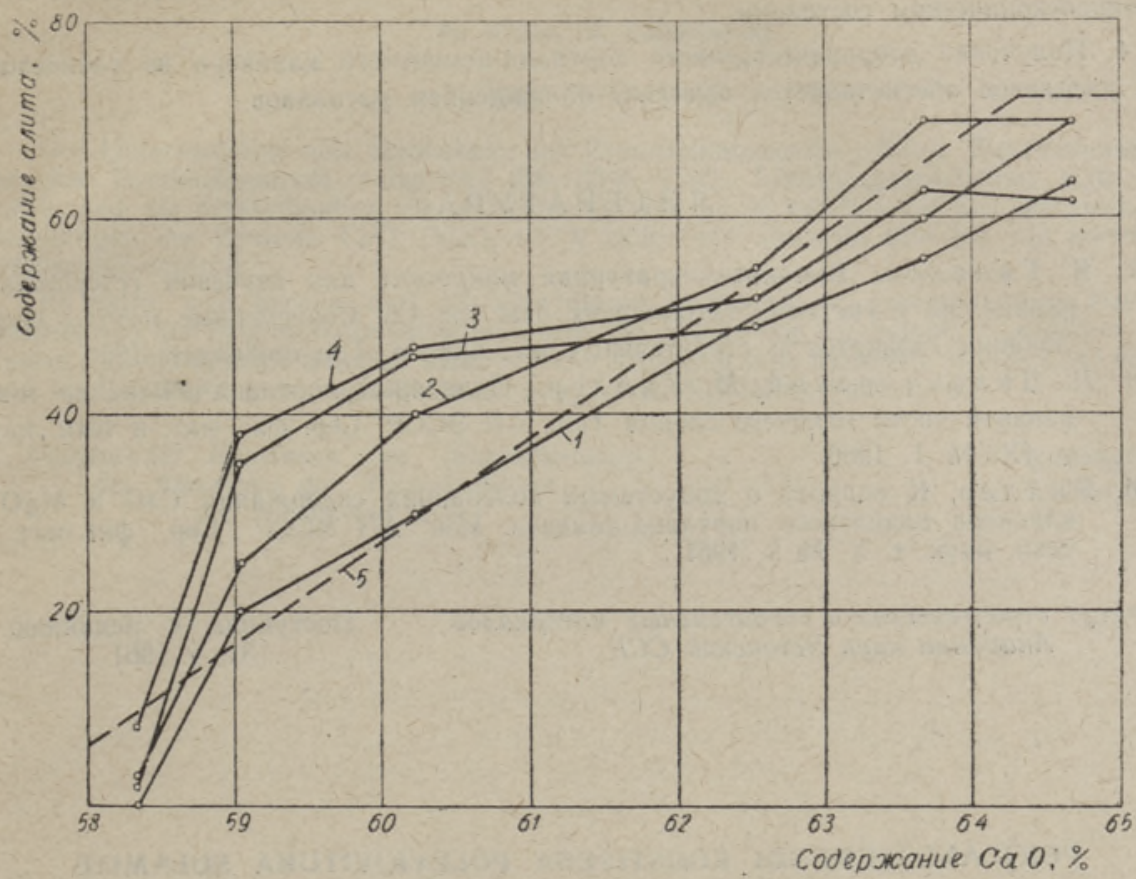

Фиг. 5. Количество алита в плавленых клинкерах: $I$ - при медленном охлажденни расплава до $1300^{\circ}$ в микропечи; 2 - при быстром охлаждении расплава в микропечи; 3 - при быстром охлаждении расплава на воздухе; 4 - при быстром охлаждении расплава в воде; 5 - рассчитанное методом Кннда.

Из всего сказанного следует, что для получения из сланцезольных расплавов качественного портланд-цементного клинкера требуется их быстрое, желательно водяное, охлаждение. Оно позволяет получить клинкер, не содержащий свободной окиси кальция и содержащий окись магния в мелкодисперсном состоянии. Количество алита в этих клинкерах, как правило, больше расчетного.

\section{Выводы}

1. Температура начала кристаллизации сланцезольных расплавов, содержащих 59-61,5\% СaO, значительно ниже соответствующей температуры в чистой трехкомпонентной системе $\mathrm{CaO}-\mathrm{Al}_{2} \mathrm{O}_{3}-\mathrm{SiO}_{2}: \quad 1800-1850^{\circ}$ (вместо 1950-2000'), а для расплавов, содержащих до $65 \% \mathrm{CaO},-$ до $2100^{\circ}$ (вместо $2150^{\circ}$ ).

2. Последовательность кристаллизации в клинкерных расплавах сильно отличается от таковой в чистой трехкомпонентной системе: $3 \mathrm{CaO} \cdot \mathrm{SiO}_{2}$ кристаллизуется, как правило, раньше $2 \mathrm{CaO} \cdot \mathrm{SiO}_{2}$, причем он имеет широкую область первичной кристаллизации, вклинивающуюся между соответствующими областями $2 \mathrm{CaO} \cdot \mathrm{SiO}_{2}$ и $\mathrm{CaO}$. Во всех расплавах кристаллизуется периклаз.

3. Минералогический состав клинкера при неравновесной крнсталлизации (быстром охлаждении) расплава отличается от состава медленно охлажденного клинкера. Быстроохлажденный плавленый клинкер 
а) содержит повышенное количество алита, особенно при низком коэффициенте насыщения, и не содержит свободной окиси кальция даже при КН=1, если расплавление проведено на $150-200^{\circ}$ выше температуры начала его кристаллизацин;

б) содержит периклаз и свободную окись кальция (если она присутствует) в субмикроскопнческом состоянии.

4. Получение доброкачественного портланд-цементного клинкера из сланцезольных расплавов обеспечивается быстрым охлаждением расплавов.

\title{
Л И Т Е Р А Т Р A
}

1. Ф. Я. Галахов, Высокотемпературная микропечь для изучения гетерогенных равновесий в системах тугоплавких окислов. Сб. Современные методы исследования силикатов и строительных материалов, Госстройиздат, 1960.

2. Н. Л. Дил акторский, М. Ки йлер, Плавленый портланд-демент из минеральной части горючего сланца. Изв. АН ЭССР. Сер. фнз.-мат. и техн.,наук, т. IX, № 1, 1960 .

3. М. Ки йле $\mathrm{p}, \mathrm{K}$ вопросу о допустимых колебаниях содержания $\mathrm{CaO}$ и $\mathrm{MgO}$ в клинкере плавленого портланд-цемента. Изв. АН ЭССР. Сер. физ.-мат. и техн, наук, т. X, № 2, 1961.

Институт строительства и строительных материалов Академии наук Эстонской ССР
Поступила в редакцию

31. V 1961

\section{PORTLANDTSEMENDI KOOSTISEGA POLLEVIVITUHA SULAMITE KRISTALLISATSIOONIST}

\author{
M. Kiiler, \\ tehniliste teaduste kandidaat \\ N. Dilaktorski, \\ geoloogia-mineraloogia doktor \\ Resünuee
}

Portlandtsemendi koostisega $(58-65 \% \quad \mathrm{CaO}$, küllastuskoefitsient $0,70-1,05)$ põlevkivituha sulamite uurimisei selgus, et nende sulamite kristallisatsioon erineb tunduvalt vastavate kolmiksüsteemi $\left(\mathrm{CaO}-\mathrm{Al}_{2} \mathrm{O}_{3}-\mathrm{SiO}_{2}\right)$ segude kristallisatsioonist ning algab palju madalamal temperatuuril.

Tehti kindlaks, et põlevkivituha sulamitest kōrgeväärtusliku portlandtsemendi saamiseks on vaja sulameid kiirelt jahutada, sest siis saadakse suure aliidisisaldusega klinker, mis sisaldab minimaalselt $\mathrm{CaO}-\mathrm{d}$ ning milles $\mathrm{MgO}$ (samuti kui $\mathrm{CaO}$ ) esineb väga peente kristallidena.

Eesti NSV Teaduste Akadeemia Ehituse ja Ehitusmaterjalide Instituut
Saabus toimetusse

31. V 1961 


\section{KRISTALLISATION VON GESCHMOLZENEN BRENNSCHIEFERASCHE-SCHICHTEN VON DER ZUSAMMENSETZUNG DES PORTLANDZEMENTS}

\section{Kiiler, N. Dilaktorski \\ Zusammenfassung}

Die Untersuchung von Schmelzen der Brennschieferasche, deren Zusammensetzung der des Portlandzements entspricht (58-65\% CaO, Sättigungskoeffizient 0,70-1,05), ergab, daß die Kristallisation dieser Schmelze von der Kristallisation der entsprechenden Mischungen des Systems $\mathrm{CaO}-\mathrm{Al}_{2} \mathrm{O}_{3}-\mathrm{SiO}_{2}$ bedeutend abweicht und bei viel niedrigerer Temperatur beginnt.

Es stellte sich heraus, daß die Gewinnung hochwertigen geschmolzènen Portlandzements aus der Brennschieferasche eine schnelle Abkühlung der Schmelze erfordert, da in diesem Fall ein Klinker erhalten wird, der viel Alite und eine minimale Menge $\mathrm{CaO}$ enthält, und in dem $\mathrm{MgO}$ (wie auch $\mathrm{CaO}$ ) in sehr feinen Kristallen verteilt ist.

\section{Institut für Bauwesen und Baumaterialien der Akademie der Wissenschaften der Estnischen SSR}

Eingegangen am 31. Mai 1961 